exposures 4.5 days, figures which are very similar to those in our published series $(11.7,6.7,4.6,5.3$ and 4.5 days respectively). We excluded from our analysis one patient found at necropsy to have a carcinoma of the bile duct and another with abnormal liver function tests who did not actually become jaundiced. More than 25 further cases were reported or followed up too late for inclusion in the analysis.

Dr. M. H. M. Dykes and his colleagues (30 Manch, p. 638) referred to our omission of details of statistical tests and to the "unquestioned qualifications of the statistical consultants available to the authors." It was preaisely because of the latter and because all the data were displayed in our paper that we did not burden readers with details of the numerous tests that were performed. A Mann-Whitney $U$ test on the pooled double- and triple-exposure groups compared with the single exposure groups gave a value (of $U$ ) such that the normal deviate (z) equalled $2.94(P=0.0016$, single-tailed). Several $t$-tests on the raw data and on various transformations of the data gave results which were consistent with the nonparametric test.

It is not possible to compare Professor Simpson's 175 post-halothane cases with our own series. Indeed, his letter suggests that the two series are not comparable in at least one important respect. The mortality of $10 \%$ in his series contrasts with the mortality of $51 \%$ in ours, suggesting that a relatively larger proportion of mild cases were included in his series. However, Professor Simpson's letter adds support to our conclusion that multiple exposures to halothane increase the risk of postoperative jaundice since only $15 \%$ of the patients in our series and $19 \%$ of the patients in Professor Simpson's series had developed jaundice after a single exposure to halothane.

Other correspondents have referred to the fact that the committee has received no reports of postoperative jaundice occurring in patients who had not received halothane as part of their anaesthetic. It is possible that anaesthetists may have neglected to report "non-halothane jaundice" and we have ourselves stressed that our data were probably highly selected. So far, however, no such reports have been received by the committee in the three months following the publication of our paper.

We have suggested that the reported death rate after multiple exposure to halothane within a period of one month was about 10 times the risk of death from infectious hepatitis among the general population in any one year. Since, however, the deaths of patients in our series occurred within two months of the most recent exposure to halothane, we may have presented an unduly optimistic comparison. The risk that a hypothetical "control" patient selected from the general population on the same day that a patient had been re-exposed to halothane would die from infectious hepatitis within a similar period could be over 60 times less than the risk to the patient re-anaesthetized with halothane.

None of your correspondents has denied the probable existence of "halothane hepatitis" as an unoommon complication of anaesthesia. Its real incidence remains to be determined and it is hoped that more complete reporting of jaundice following anaesthesia with any agent will clarify the situation.-We are, etc.,

W. H. W. INMAN

Committee on Safety of Medicines, ondon E.C.2

W. W. Mushin

Department of Anaesthetics

Welsh National School of Medicine, Cardifi

SIR,-The methods by which the Committee on Safety of Medicines collects information about events that are suspected of being due to the adverse effect of a drug are well known in the United Kingdom, but it is understandable that they should be less well known elsewhere. It may therefore be helpful if I answer briefly the questions asked by Dr. M. H. M. Dykes and his colleagues (30 March, p. 638) following Dr. W. H. W. Inman and Professor W. W. Mushin's paper (5 January, p. 5 ).

(1) In the United Kingdom reports are requested from all doctors and dentists who observe adverse effects in patients under their care, the Registrar-General, who recives reports of deaths attributed to the use of drugs, coroners, and the pharmaceutical industry.

(2) The amount of information routinely requested is specified on special reporting cards. I have sent one to Dr. Dykes and will be glad to provide copies for other doctors on request.

(3) The scientific staff of the committee examine and classify all reports individually. The aotion taken subsequently depends on the nature of the report. Validation of all reported drug reactions is not undertaken routinely, but additional information is sought about specific cases when new risks are suspected or old risks require to be evaluated. This may involve correspondence with the doctor who reported the effect or he may be visited by one of the 80 parttime medical officers who assist the committee in different parts of the country. A detailed study of a random sample of the reports has shown that they are made responsibly. 1

(4) It is impracticable to define "specific diagnostic criteria" before classifying a reaction as probably, or possibly, or not due to a particular drug. Firstly, the committee would have to adopt different oriteria for each reaction. Secondly, reports are received from a wide variety of doctors practising under different conditions with different facilities. Thirdly and most importantly, it is impossible to formulate diagnostic criteria for a new reaction before it is recognized, and any attempt to do so would serve only to prevent the oommittee from alerting the profession to a previously unsuspected hazard.

More detailed accounts of the committee's adverse reactions system have been published elsewhere. ${ }^{2}$-I am, etc.,

David MANSEL-JONES

Committee on Safety of Medicines, Condon E.C.2

1 Inman, W. H. W., and Evans, D. A. P., British Medical fournal, 1972, 3, 746 .

2 McLachlan, G., ed., Portfolio for Health 2, p. 63. London, Oxford University Press, 1973.

World Health Organization, Technical Report
Series No. 498, P. 37. Geneva, WH.O., 1972.
Dangerous Patients

SIR,-The leading article (23 March, p. 527) under this head confuses the issue. The problem is not the law but the material provision. Fourteen years ago the British Medical Association ${ }^{1}$ together with other concerned bodies suggested remedies. To the present time little has been done despite the urgency of the problem, though it is understood that new and construative proposals along the lines previously recommended are imminent.

The special hospitals are out of date, overcrowded, too big, too centralized, too divorced from other types of provision. A number of smaller units with facilities for investigation and research and with closer links with the mental health service generally are needed, with regional affiliations. There is a need for development of forensic psychiatry, of relevant aspects of the social services, and of the penal system in close association. Present developments reduce the need for a clear distinction between the "criminal lunatic" and the "criminal." It is all too easy under the law as it exists to lock up anyone who is thought to be dangerous. Long before 1959 admissions to Rampton were commonly of patients who had made no court appearance but who were a trouble to manage in local hospitals. In section 97 of the Mental Health Act the phrase is "dangerous, violent or criminal." The main bar to admission to secure units is lack of space. The proposed "medium" security units might acoommodate some of those not meeding "maximum" security. But "medium" security implies adequate staffing. Meanwhile there seems no reason why, if prison conditions could be made suitable, some of those who are a continuing danger to society could not be more appropriately lodged there.-I am, etc.,

BRIAN KIRMAN

Queen Mary's Hospital for Children,

Carshalton, Surrey

1 British Medical fournal, Supplement, 1960, 2, 228.

SIR,-Your leading article (23 March, p. 527) raises a point of increasing importance at the present time. Is it not time that both psychiatrists and their patients realized that there are patients who require secure (locked ward) accommodation, not for punishment, as seems to be constantly implied, but because of the nature of their symptoms, which of course they cannot help.

I would have thought they were entitled to these facilities rather than being allowed out to commit crimes, be social pests in the community, or kill themselves.-I am, etc., Littlemore Hospital,

J. ELWES DUFFIELD Oxford

\section{Chronic Brucellosis}

SIR,-Your leading article (23 February, p. 299) needs the following comment. The statement that the examination of the patient's blood for brucella antibodies may lsad to the diagnosis is obviously correct, but the following remark that if the agglutination test, the mercaptoethanol test, the complement fixation test, and the antihuman globulin test are all negative the diagnosis 
can be excluded is false. This must be emphasized because patients can have all the signs and symptoms of brucellosis without any demonstrable antibodies. The following case history illustrates the truth of this statement.

In May 1967 a 37-year-old man stayed on a farm during an abortion storm and drank raw infected milk every day. On 8 July 1967 he was thought to have "flu" and was in bed for a fortnight with a very severe headache, general aches and pains, and sweating which was so severe that he gave up wearing pyjamas. He was treated for a he gave up wearing pyjamas. He was treated for a
viral infection and was given tetracycline for three viral infection and was given tetracycline for three
weeks. He felt fit until $29 \mathrm{July}$, when his symptoms weeks. He felt fit until $29 \mathrm{July}$, when his symptoms
returned. On 1 August brucellosis was diagnosed returned. On 1 August brucellosis was diagn
and he was admitted to hospital on 5 August.

Blood culture taken on 8 August grew Brucella abortus biotype 1 ; this was reported on 27 September and he began treatment with tetracycline and streptomycin for a month with a good response. At the end of October 1967 he had a relapse. He had a further relapse lasting 14 days in May 1968, when his spleen was found to be palpable. On 1 July he was given an intradermal injection of brucellin. The next day he felt a little unwell, and on 3 July The next day he felt a little unwell, and on 3 July
the brucellin test when read was completely negative.

He had two further relapses, in November 1969 and August 1970, and was treated each time with tetracycline. When seen on 1 March 1973 he had been complaining of severe mental depression and feeling tired. This commenced a week after an influenza vaccine injection in December. He an influenza vaccine injection in December. He thought he had "flu" and could not understand the symptoms because of his recent vaccination. Since then he has greatly improved, and
last seen was feeling tired but much better.

Over a period of years his blood was examined and the serum agglutination, antihuman globulin (Coombs), and complement fixation tests carried out. These were done on seven occasions between 1969 and 1973 with negative results. Three sera were examined using an antigen prepared from the organism isolated from the patient's blood, also the organism isolated from the patient's blood, also with negative results. In blood taken on 21 May
1968 the serum IgM level was $104 \mathrm{mg} / 100 \mathrm{ml}$ (normal range 50-170).

In the past I have received numerous specimens from patients complaining of symptoms suggestive of brucellosis who were in close contact with infected cattle. The question must arise, when it is impossible to demonstrate antibdies to brucella and no oiher diagnosis has been made, as to whether these patients are suffering from brucellosis, particularly in the light of the case quoted. Unfortunately blood cultures yielding $\mathrm{Br}$. abortus are rare in brucellosis except in the acute case; hence the difficulty in establishing the diagnosis of brucellosis in a patient who does not produce antibodies.

One furcher point in the leading article that I would like to take up is the statement that the acute disease usually dies out in the patient within a year of infection. I wonder how many people would agree with this statement? Certainly it is no reason to allow a case of acute brucellosis to go untreated, and such an action or lack of action would amount to negligence. The acute case generally readily responds to treatment, while in the chronic case treatment is extremely difficult and very disappointing. No one who has made the diagnosis of brucellosis in the acute stage should neglect to give adequate antibiotic therapy for at least six weeks.I am, etc., Public Health Laboratory,
St. Mary's General Hospital, Portsmouth

Donald J. H. Payne

\section{Coping with Minor Casualties}

SIR,-Before more words are wasted would someone please define "minor casualty" for me? Mr. D. Lamont (23 March, p. 573) ap- pears to believe that the ambulant state of the patient is the criterion.

The "young man" he advocates for the "lowny function" of "eliminator" will fail to diagnose the ruptured metacanpophalangeal ligament or the severed tendon or nerve concealed beneath the most trivial of outs if he is denied the right to perform a full, unhurried examination of the injured part. He would also need more than an "apartment" to provide tetanus prophylaxis, simple dressings, and "etc [?]." Heaven forbid that he should even think about removing foreign bodies from eyes in inadequate surroundings and without proper examination.

It is not the ambulant patients who block the casualty officer's time; it is the ubiquitous "collapse". These patients are all brought by ambulance in response to 999 calls and all require full examination. But most of these are cases of social prob.ems, long-standing abdominal pains, minor cerebrovascular accidents, faints, drunks, hysterics, and various psychosomatic disorders, all of which require a great deal of time to sort out and which, I feel, could be dealt with far more effectively and efficiently by the G.P.

Surely if an eliminator is required in a casualty department, he should be the most experienced doctor available and not "the most junior nedical member of the staff". -I am, etc.,

Accident Department

Peter Catlin Nottingham General Hospital, Nottingham

SIR,-When one reads the correspondence on "Coping with Minor Casualties," and especially about the poor fellow who had his Sunday lunch disturbed, one wonders what on earth the present-day doctor is in practice for.-I am, etc.,

Frinton-on-Sea, Essex

\section{W. H. SCOTT-EASTON}

\section{Treatment of Meningococcal Carriers}

SIR,-With reference to the paper by Dr. D. M. Easton and others (16 March, p. 507), I feel that I should point out that the statement that tetracyclines are not effecive in the treatment of nasopharyngeal meningococcal carrier states is incorrect for the most recent of the tetracycline antibiotics-namely, minocycline (7-dimethylamino-6-deoxy-6-demethyl tetracycline).

It has been shown ${ }^{1-6}$ that minocycline 100 mg twice daily for a period of probably not less than five days significantly reduces the number of nasopharyngeal carriers of meningococci. In the studies completed to date there has been no evidence of resistance of Neisseria meningitidis to minocycline.-I am, etc.,

A. YEadon

Gosport, Hants

Medical Director,

1 Devine, L. F., et al., American fournal of Epidemiology, i973, 97, 394.

2 Devine, L. F., Hannah, J. M., Hogerman, C. R., Rhodes, L., and Peckingau

3 Guttler, R. B., and Beaty, H. N., Antimicrobial Agents and Chemotherapy, 1972, 1, 397.

Guttler, R. B., Counts, G. W., Avent, C. K., and Beaty, $\mathrm{H}$. N., Fournal of Infectious Diseases, 1971, 124, 199.

5 Devine, L. F, et al., American fournal of Epidemiology, i' i971, 93, 337. demiology, 1971, 93, 337 .
Ito, S., et al. Medical Consultation and New
Remedies, 1972, 9, 127 .
Effects of Oral Contraceptives on Endogenous Hormone Secretion

SIR,-We were interested in the comments of Drs. H. S. Jacobs and Anne M. Jequier (23 February, p. 328) concerning our paper on the effects on endogenous hormone secretion of a combined low-oestrogen contraceptive containing mestranol (5 January, p. 11).

Though we agree that the urinary assay for luteinizing hormone is not specific for biologically active hormone, never.heless it does detect the presence of LH fragments, whether desialylated or not, which have been derived from pituitary LH. We therefore consider that this is a useful measure of pituitary activity which we have used as a means of comparing cycles with and without the exhibition of a low-dose oestrogen oral contraceptive. Furthermore, as we indicate in our paper, urinary LH levels measured by precisely the same technique have been previously used by one of us in the assessment of the effects of different contraceptive formulations. In these previously reported studies 1 we found a more significant inhibition of $\mathrm{LH}$ with the higher-dose norethisterone-containing preparations which also contained ethinyl oestradiol. It is probable therefore that these differences are primarily related to an effect of mestranol or perhaps the lower dose of norethisterone.

The other more significant point we wish to make concerns the high output of oestrogen in some of the oral-contraceptivetreated cycles. The fact that there was this evidence of marked ovarian activity in the absence of ovulation in two of these women and that active steroidogenesis was taking place in most of the other treatment cycles merits further comment and investigation.

We await with interest the results of the studies of Drs. Jacob and Jequier, particularly as they suggest that there may be differences in the effects of ethinyl oestradiol and mestranol on the pituitary ovarian mechanism, as suggested in our paper.-We are, etc.,

MAX ELSTEIN

Department of Human Reproduction and Obstetrics,

University of Southimpton

HAROLD MILLER

Portsmouth and Is

Portsmouth

1 Orr, A. H., and Elstein, M., fournal of Endocrinology, 1969, 43, 617.

\section{Contraception and Abortion}

SIR,-King's Termination Study II (9 March, p. 418) really tells us very little that is new and also draws some conclusions for which no basis exists in the published findings.

It is widely accepted that the closer the doctor-patient relationship the better are the results of treatment. The King's College Hospital figures have shown that this is also true when applied to enthusiastic contraceptive advice and its success. However, I remain to be convinced that it was necessary for them to carry out 360 abortions as a neossary prelude to this suocess. A less liberal but equally compassionate approach (the two are not mutually exclusive) to requests for termination, coupled with proper contraceptive advice and enthusiastic follow- 